Manuscript Number: ENGSTRUCT-D-16-00905R2

Title: Mechanical model for determining the critical load of plane frames with semi-rigid joints subjected to static loads

Article Type: Research Paper

Keywords: Model; frame; semi-rigid; connections; elastic; buckling load.

Corresponding Author: Dr. Messaoud Saidani, Ph.D.

Corresponding Author's Institution: Coventry University

First Author: Abd Nacer T Ihaddoudene, PhD

Order of Authors: Abd Nacer T Ihaddoudene, PhD; Messaoud Saidani, Ph.D.; Jean-Pierre Jaspart, PhD, Prof

Abstract: The present work deals with the effect of beam-column joint flexibility on the elastic buckling load of plane steel frames. A simple and effective mechanical model is proposed and the corresponding stiffness matrix is presented. The model consists in the development of comprehensive approach taking into account, simultaneously, the effects of the joint rigidity, the elastic buckling load, and this for both sway and non-sway frames. As has been shown by previous research, only one element is required over the length of the element to model stability. This is a marked contribution and advantage of the proposed method, as well as its simplicity, and yet accuracy, to solve practical problem with little computational effort. Also, it includes stability functions in the stiffness matrix, something very often ignored by researchers. Numerical results are obtained for frames with various characteristics and support conditions when three illustrative examples from the literature are presented and discussed. The elastic buckling load is found to be strongly affected by semi-rigid joints and reveals that the proposed model is computationally very efficient with the expressions presented being general. The paper makes reference to the Eurocode 3 approach and those of other researchers in comparing the results. The proposed method is found to be more effective and simple to use, and yielding to very good results. 
Coventry University

School of Energy, Construction and Environment

Much park Street

Coventry CV1 5FB

Telephone 02476888166

Fax 02476888296

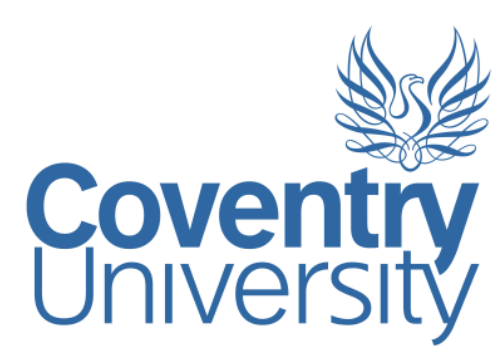

12 April 2017

The Regional Editor (Europe)

Professor Herbert Mang

International Journal Engineering Structures

Dear Professor Mang,

On behalf of my co-authors, I would like to thank you for the opportunity to resubmit a revised copy of this manuscript entitled "Mechanical model for determining the critical load of plane frames with semi-rigid joints subjected to static". I would also like to take this opportunity to express our thanks to the reviewers for the positive feedback and helpful comments that have led to the improvements.

Using feedback received from the reviewers, the article has undergone major revisions to its content. A new section has been added, entitled "Significance of the research", new material has also been added to the Introduction, and the references list revised accordingly. The contribution to knowledge of the article is now more firmly established and clearly spelled out.

We believe have resulted in an improved revised manuscript, which you will find uploaded alongside this document. The manuscript has been revised to address the reviewer comments, which are appended alongside our responses to this letter.

We have also included a separate document that highlights the differences between the work of Chen et al. that the reviewer referred to and the current study. This was not included in the article as it was not an aim in itself, however it is now referred to and briefly described in the revised manuscript.

We very much hope the revised manuscript is accepted for publication in the Journal.

Kind Regards,

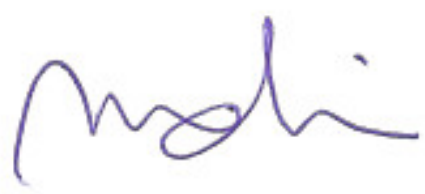

Messaoud Saidani, BEng, PhD, PgCertLT, CEng, MIStructE

Tel/Fax: ++44 2477658385

E-mail: m.saidani@coventry.ac.uk

\author{
Faculty of Engineering, Environment \& Computing \\ Direct Line \\ Fax
}

www.coventry.ac.uk 


\section{Detailed Response to Reviewer}

A.N.T. Ihaddoudène, M. Saidani and J.P. Jaspart

We would also like to take this opportunity to express our thanks to the reviewer for the positive feedback and helpful comments that have led to the improvements.

Using feedback received, the article has undergone major revisions to its content. A new section has been added, entitled "Significance of the research", new material has also been added to the Introduction, and the references list revised accordingly. The contribution to knowledge of the article is now more firmly established and clearly spelled out.

We believe have resulted in an improved revised manuscript, which you will find uploaded alongside this document. The manuscript has been revised to address the reviewer comments, which are appended alongside our responses to this letter.

Also included below, is a separate document that highlights the differences between the work of Chen et al. that the reviewer referred to and the current study. This was not included in the article as it was not an aim in itself, however it is now referred to and briefly described in the revised manuscript.

We very much hope the revised manuscript has satisfactorily addressed the comments made.

Yours Sincerely,

A.N.T. Ihaddoudène, M. Saidani and J.P. Jaspart

April 2017 


\section{Comparison between Chen et al. ${ }^{*}$ formulation and that of the authors' current study}

The governing differential equations of a beam-column are solved in an exact form. By using the equilibrium equations based on the deformed shape of a beam-column, a complete set of slope deflection equations is obtained. The functions were restated and tabulated in a form suitable analysis by Livesley and Chandler (among others). For the beam element subjected to end moments and axial load, Chen presented the expressions of the end moments as:

$$
\begin{gathered}
M_{A}=\frac{E I}{L}\left(S_{i i} \theta_{A}+S_{i j} \theta_{B}\right) \\
M_{B}=\frac{E I}{L}\left(S_{j i} \theta_{A}+S_{j j} \theta_{B}\right) \\
P=\frac{E I}{L} \delta
\end{gathered}
$$

In compression when $P<0$,

$$
\begin{aligned}
S_{i i} & =\frac{k L \sin k L-(k L)^{2} \cos k L}{2-2 \cos k L-k L \sin k L} \\
S_{i j} & =\frac{(k L)^{2}-k L \sin k L}{2-2 \cos k L-k L \sin k L}
\end{aligned}
$$

Expressions (4) and (5) represent the stability functions and in the matrix form as:

$$
\left(\begin{array}{l}
M_{A} \\
M_{B} \\
P
\end{array}\right)=\frac{E I}{L}\left(\begin{array}{ccc}
S_{i i} & S_{i j} & 0 \\
S_{i j} & S_{j j} & 0 \\
0 & 0 & A / I
\end{array}\right)\left(\begin{array}{l}
\theta_{A} \\
\theta_{B} \\
\delta
\end{array}\right)
$$

$S_{i i}$ et $S_{i j}$ are the stability functions ( presented by W.F.Chen) for stiffness under the action of the predominant axial force. In his proposed method, using the beamcolumn stiffness degradation approach and the stability functions, divergence occurs when the axial force of member is close to zero. 


$$
\begin{aligned}
& S_{i i}=4+\frac{2 \pi^{2} \rho}{15}-\frac{(0,01 \rho+0,543) \rho^{2}}{4+\rho}-\frac{(0,004 \rho+0,285) \rho^{2}}{8,183+\rho} \\
& S_{i j}=2-\frac{\pi^{2} \rho}{30}+\frac{(0,01 \rho+0,543) \rho^{2}}{4+\rho}-\frac{(0,004 \rho+0,285) \rho^{2}}{8,183+\rho}
\end{aligned}
$$

The author has presented the stiffness matrix of a beam-column based on the stability functions in a form that shows the correction factor to the basic first-order matrix:

$$
[K]=\frac{E I}{L}\left(\begin{array}{cccccc}
\frac{A}{L} & 0 & 0 & \frac{A}{L} & 0 & 0 \\
& \frac{12}{L^{2}} \phi_{1} & \frac{6}{L} \phi_{2} & 0 & -\frac{12}{L^{2}} \phi_{1} & \frac{6}{L} \phi_{2} \\
& & 4 \phi_{3} & 0 & -\frac{6}{L} \phi_{2} & 2 \phi_{4} \\
& & \frac{A}{L} & 0 & 0 \\
S Y M & & & \frac{12}{L^{2}} \phi_{1} & -\frac{6}{L} \phi_{2} \\
& & & & & 4 \phi_{3}
\end{array}\right)
$$

Where ; $\phi_{j}(j=1,2,3,4)$

Table (1): The correction functions due to the axial load are given below

\begin{tabular}{|c|c|c|c|}
\hline$\phi_{j}$ & $P<0$ & $P=0$ & $P>0$ \\
\hline$\phi_{1}$ & $\frac{(k L)^{3} \sin k L}{12 \phi_{c}}$ & 1 & $\frac{(k L)^{3} \sinh k L}{12 \phi_{t}}$ \\
\hline$\phi_{2}$ & $\frac{(k L)^{2}(1-\cos k L)}{6 \phi_{c}}$ & 1 & $\frac{(k L)^{2}(\cosh k L-1)}{6 \phi_{t}}$ \\
\hline$\phi_{3}$ & $\frac{k L(\sin k L-k L \cos k L)}{4 \phi_{c}}$ & 1 & $\frac{k L(k L \cosh k L-\sinh k L)}{4 \phi_{t}}$ \\
\hline$\phi_{4}$ & $\frac{k L(k L-\sin k L)}{2 \phi_{c}}$ & 1 & $\frac{k L(\sinh k L-k L)}{2 \phi_{t}}$ \\
\hline
\end{tabular}


With

$\phi_{c}=2-2 \cos k L-k L \sin k L \quad$ et $\quad \phi_{t}=2-2 \cosh k L+k L \sinh k L$

Where

$\phi=\left\{\frac{1}{12}+\sum_{n=1}^{\infty} \frac{2(n+1)}{(2 n+4) !}\left[(k L)^{2}\right]^{n}\right\}$

To account for semi-rigid joints with springs constants at both ends of an element, the author (W.F.Chen) has just modified the slope deflection equations in Eq.(8.a) to Eq.(8.h).For the beam element below, the expressions of the end moments are:

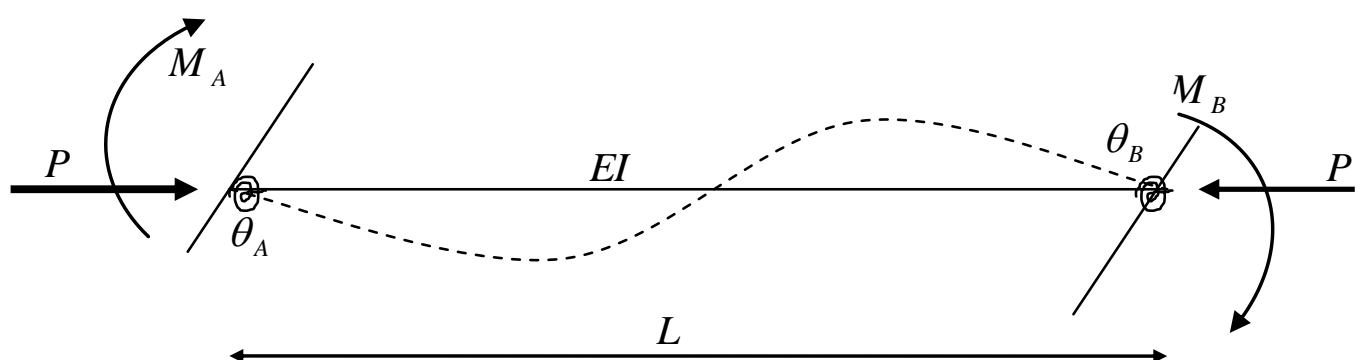

$$
\begin{aligned}
& M_{A}=\frac{E I}{L}\left[S_{i i}\left(\theta_{A}-\frac{M_{A}}{R_{k i A}}\right)+S_{i j}\left(\theta_{B}-\frac{M_{B}}{R_{k i B}}\right)\right] \\
& M_{B}=\frac{E I}{L}\left[S_{i j}\left(\theta_{A}-\frac{M_{A}}{R_{k i A}}\right)+S_{j j}\left(\theta_{B}-\frac{M_{B}}{R_{k i B}}\right)\right]
\end{aligned}
$$

Here, the end moments and the stability functions $S_{i i}$ et $S_{i j}$ previously defined have the form:

$$
\begin{aligned}
& M_{A}=\frac{E I}{L}\left[S_{i i}^{*} \theta_{A}+S_{i j}^{*} \theta_{B}\right] \\
& M_{B}=\frac{E I}{L}\left[S_{i j}^{*} \theta_{A}+S_{j j}^{*} \theta_{B}\right]
\end{aligned}
$$

Where :

$$
S_{i i}^{*}=\left(S_{i i}+\frac{E I S_{i i}^{2}}{L R_{k i B}}-\frac{E I S_{i j}^{2}}{L R_{k i B}}\right) / R^{*}
$$




$$
\begin{gathered}
S_{j j}^{*}=\left(S_{i i}+\frac{E I S_{i i}^{2}}{L R_{k i A}}-\frac{E I S_{i j}^{2}}{L R_{k i A}}\right) / R^{*} \\
S_{i j}^{*}=S_{j i}^{*}=S_{i j} / R^{*} \\
R^{*}=\left(1+\frac{E I S_{i i}}{L R_{k i A}}\right)\left(1+\frac{E I S_{i i}}{L R_{k i B}}\right)-\left(\frac{E I}{L}\right)^{2} \frac{S_{i j}^{2}}{R_{k i A} R_{k i B}} \\
\left(\begin{array}{l}
P \\
M_{A} \\
M_{B}
\end{array}\right)=\frac{E I}{L}\left(\begin{array}{ccc}
A / I & 0 & 0 \\
0 & S_{i i}^{*} & S_{i j}^{*} \\
0 & S_{j i}^{*} & S_{j j}^{*}
\end{array}\right)\left(\begin{array}{l}
u \\
\theta_{A} \\
\theta_{B}
\end{array}\right)
\end{gathered}
$$

And the stiffness matrix $[K]$ is written in the form:

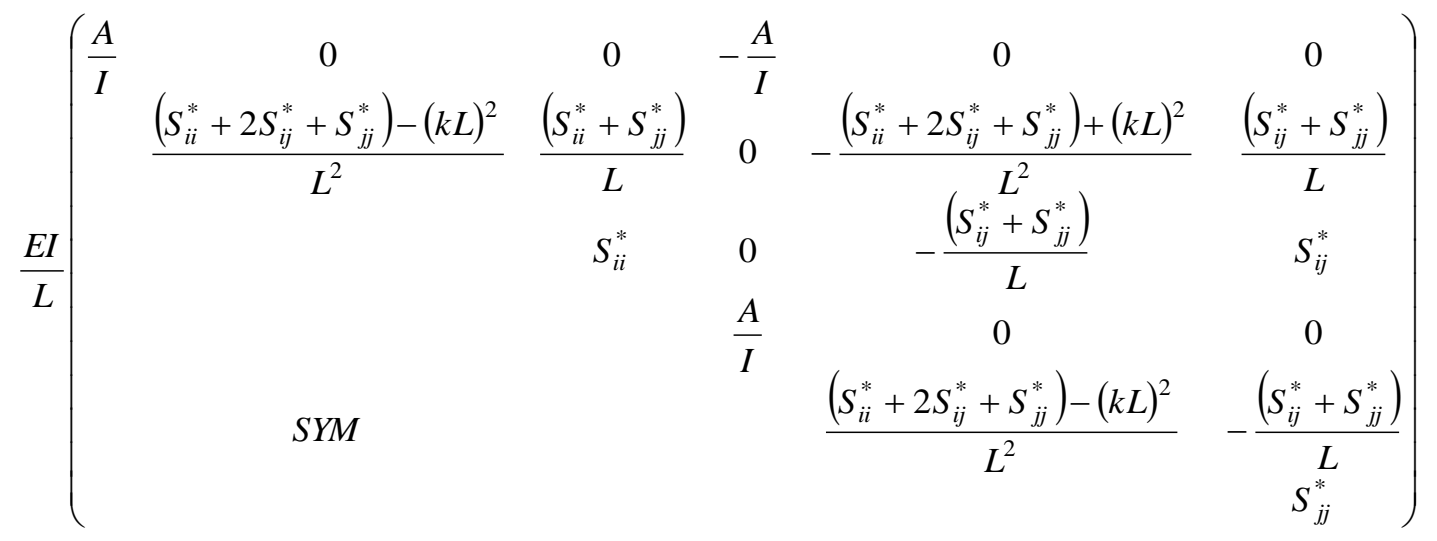

When the axial force is neglected its form is as below:

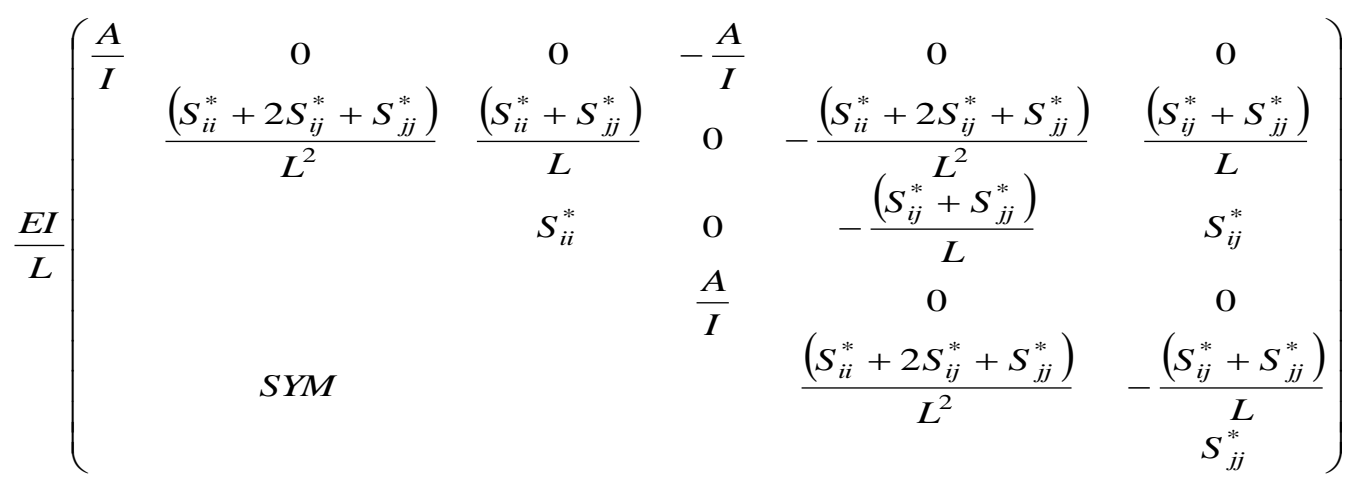




\section{ADOPTED MODEL}

The modeling adopted consists in establishing the stiffness matrix of the element with semi-rigid connections taking into account buckling. In the simplified form, the stiffness matrix in the local coordinate system is:

$$
\left[\bar{K}_{e}\right]=E I\left[\begin{array}{cccc}
\frac{v^{3}(s+\Omega)}{D l^{3}} & -\frac{v^{2}\left(1-c+\eta_{2}\right)}{D l^{2}} & -\frac{v^{3}(s+\Omega)}{D l^{3}} & \frac{v^{2}\left(1-c+\eta_{1}\right)}{D l^{2}} \\
\frac{v\left(s-v c+v \eta_{2}\right)}{D l} & \frac{v^{2}\left(1-c+\eta_{2}\right)}{D l^{2}} & \frac{v(v-s)}{D l} \\
& \frac{v^{3}(s+\Omega)}{D l^{3}} & \frac{v^{2}\left(1-c+\eta_{1}\right)}{D l^{2}} \\
S Y M & & & \frac{v\left(s-v c+v \eta_{1}\right)}{D l}
\end{array}\right]
$$

Where:

$$
\begin{aligned}
& D=(2-2 \cos v-v \sin v)+\xi\left(v, k_{1}, k_{2}\right) \\
& \Omega=\left(k_{1}+k_{2}\right) v w c-k_{1} k_{2}(v w)^{2} s \\
& \eta_{1}=k_{1} v w s \text { et } \eta_{2}=k_{2} v w s
\end{aligned}
$$

The stiffness matrix ( 12 ) proposed, can be directly used to formulate the linear, and all non-linear aspects (geometric and material) stiffness matrices( with or without semi-rigid joints).Those expressions allow for the variation of the stiffness of a member in the presence of :(a) predominant axial force with semi-rigid joints, (b)predominant axial force without semi-rigid joints, (c) semi-rigid action without axial load; used to revise the stiffness matrix comprising more elements as well as predicting the buckling of a single element. The following Table (2) shows, for example $k_{2 j}$, the difference between these elements of the stiffness matrix and those when the behavior of the semi-rigid connection is ignored. 
Table (2): $k_{2 j}$ expressions for different cases

\begin{tabular}{|c|c|}
\hline $\begin{array}{c}\text { When both axial force and semi- } \\
\text { rigid connection are accounted. }\end{array}$ & $\begin{array}{l}\text { When only axial force is } \\
\text { taken into account }\end{array}$ \\
\hline$k_{21}=\frac{E I}{l^{2}} \frac{v^{2}\left[1-\cos v+k_{2} v w \sin v\right]}{D}$ & $k_{21}=\frac{E I}{l^{2}} \frac{v^{2}[1-\cos v]}{(2-2 \cos v-v \sin v)}$ \\
$k_{22}=\frac{E I}{l} \frac{v\left[\sin v-v \cos v+k_{2} v^{2} w \sin v\right]}{D}$ & $k_{22}=\frac{E I}{l} \frac{v[\sin v-v \cos v]}{(2-2 \cos v-v \sin v)}$ \\
$k_{23}=-\frac{E I}{l^{2}} \frac{v^{2}\left[1-\cos v+k_{2} v w \sin v\right]}{D}$ & $k_{23}=-\frac{E I}{l^{2}} \frac{v^{2}[1-\cos v]}{(2-2 \cos v-v \sin v)}$ \\
$k_{24}=\frac{E I}{l} \frac{v[v-\sin v]}{D}$ & $k_{24}=\frac{E I}{l} \frac{v[v-\sin v]}{(2-2 \cos v-v \sin v)}$ \\
\hline
\end{tabular}

The objective of the paper is not to investigate the characteristics, merits and limitations of element and formulation, only the method presented by the author is describe. Some remarks can be made:

1- The element stiffness matrix derived by the stability functions and many others formulations are all different, not only in the method of derivation but also their accuracy and efficiency. Even under the name of stability function, there may still be different versions used varied forms for the analysis (Majid (1972), Livesley (1964), Oran (1973), Chen (1991), Chan(2000)...).

2- The stability functions reflect the decrease in the flexural rigidity of a column as a function of the compression force applied to it. In fact, they modify the moment-rotation relations. The expression of these moments is given by the slope-deflection method (Chen et al.) in which we mainly find the functions of stability $S_{i i}$ and $S_{i j}$.

3- The generalization of formulated expressions consider different cases of behavior of rigid, semi rigid linear analysis and of a plastic analysis and finally the stability analysis. Thus, the analytical confrontation of the expressions given by the established formulation makes it possible to consider or not the effect of the axial force without having to develop an artifice of calculation to remove the indeterminacy or divergence, for example, as is the case with some authors (W.F.Chen). 
4- The proposed method, although simple provides a wide range of applications. It is based on the matrix formulation of stability functions of beam-column witch can take on consideration the effects of axial force and a semi- rigid joints explicitly. The verification examples of the method showed a good accuracy. Compared with EC3 code and other formulations, the method shows its accuracy, simplicity and generality. It can be run easily on personal computer.

\section{Reference:}

${ }^{*}$ Chen W.F., Kishi N., Komuro M. "Semi-rigid connections handbook". J. Ross Publishing, Civil and Environmental Engineering Series. 2011. 


\section{Highlights}

- A model for determining the elastic buckling load of steel frames

- Model takes into account the rigidity of the joints

- Explicit formulations are given

- Frames with different characteristics and support conditions are considered

- Results from model agree with published results obtained using other approaches 


\begin{abstract}
The present work deals with the effect of beam-column joint flexibility on the elastic buckling load of plane steel frames. A simple and effective mechanical model is proposed and the corresponding stiffness matrix is presented. The model consists in the development of comprehensive approach taking into account, simultaneously, the effects of the joint rigidity, the elastic buckling load, and this for both sway and non-sway frames. As has been shown by previous research, only one element is required over the length of the element to model stability. This is a marked contribution and advantage of the proposed method, as well as its simplicity, and yet accuracy, to solve practical problem with little computational effort. Also, it includes stability functions in the stiffness matrix, something very often ignored by researchers. Numerical results are obtained for frames with various characteristics and support conditions when three illustrative examples from the literature are presented and discussed. The elastic buckling load is found to be strongly affected by semi-rigid joints and reveals that the proposed model is computationally very efficient with the expressions presented being general. The paper makes reference to the Eurocode 3 approach and those of other researchers in comparing the results. The proposed method is found to be more effective and simple to use, and yielding to very good results.
\end{abstract}




\title{
Mechanical model for determining the critical load of plane frames with semi-rigid joints subjected to static loads
}

\author{
A.N.T. Ihaddoudène ${ }^{1}$, M. Saidani ${ }^{2, a}$ and J.P. Jaspart ${ }^{3}$ \\ ${ }^{1}$ Built Environment Research Laboratory, Faculty of Civil Engineering, U.S.T.H.B., Algeria \\ ${ }^{2, a}$ Faculty of Engineering, Environment and Computing, School of Energy, Construction and \\ Environment, Coventry University, Priory Street, Coventry CV1 5FB, England, UK. \\ ${ }^{3}$ Faculty of Applied Sciences, Department ArGEnCo, Liège University, 4000 Liège 1,
} Belgium.

\begin{abstract}
The present work deals with the effect of beam-column joint flexibility on the elastic buckling load of plane steel frames. A simple and effective mechanical model is proposed and the corresponding stiffness matrix is presented. The model consists in the development of comprehensive approach taking into account, simultaneously, the effects of the joint rigidity, the elastic buckling load, and this for both sway and non-sway frames. As has been shown by previous research, only one element is required over the length of the element to model stability. This is a marked contribution and advantage of the proposed method, as well as its simplicity, and yet accuracy, to solve practical problem with little computational effort. Also, it includes stability functions in the stiffness matrix, something very often ignored by researchers. Numerical results are obtained for frames with various characteristics and support conditions when three illustrative examples from the literature are presented and discussed. The elastic buckling load is found to be strongly affected by semi-rigid joints and reveals that the proposed model is computationally very efficient with the expressions presented being general. The paper makes reference to the Eurocode 3 approach and those of other researchers in comparing the results. The proposed method is found to be more effective and simple to use, and yielding to very good results.
\end{abstract}

Keywords: Model - Frame - semi rigid - connections - elastic - buckling load

\footnotetext{
${ }^{\mathrm{a}}$ Tel: +44 0 2477658385; fax: +44 0 2477658365. E-Mail address: m.saidani@ coventry.ac.uk
} 


\section{Notations}

$k_{1}, k_{2}: \quad$ Elastic constants of the springs in rotation at the nodes " $i$ "and " $j$ ", respectively

$D \quad$ : $\quad$ Denominator for the case where both the second order effects and rigidity of the joints are considered

$D_{1} \quad$ : $\quad$ Denominator for the case where only the rigidity of joints is considered

w : $\quad$ Flexural rigidity per unit length $\frac{E I}{l}$

$\zeta_{i}(v), \phi_{i}(v)$ : Functions including both axial forces and the rigidity of the joint for different situations

\section{Introduction}

Conventional analysis and design of steel frames assume either perfectly rigid or pinned joints. However, as is now well established, the real behaviour of the joints is between these two extreme cases: the most rigid joints always have some flexibility so that the joints are capable of transmitting a bending moment, whereas the pinned joints case always exhibit some rotational rigidity. In this intermediate case of semi rigid joints, some rotation with corresponding bending moments will develop between the beam and column elements. The concept of semi rigid joints in steel structures is well accepted [1-8]. Previous studies have indicated that in frame analysis, joint rotational behaviour must be considered. It is therefore necessary to incorporate the effect of joint flexibility in the frame analysis, otherwise the resulting internal forces and bending moments will contain errors [9-14].

Mathematical models were proposed in the past to fit the moment-rotation $(M-\theta)$ curves of joints, with various levels of complexity, using experimental data [1-4, 9]. The response of the joint is dependent on the geometric and mechanical properties of its components. Because of the high number of the parameters influencing the behaviour of connections, accurate modeling of such behaviour becomes very complex. Globally, initial rigidity and the ultimate moment of the connection are the two most important [15]. 
Significant research has been carried out using mechanical models to study the joint's behaviour and to introduce their effect in the analysis of structures. Simões da Silva [12] proposed a generic model for steel joints under generalized loading. Ihaddoudène [16] presented a mechanical model of the connections, where the rigidity of the joint is represented by means of rotational and translational springs introducing the concept of non deformable element of nodes, thus describing relative displacements and rotations between the nodes and the elements of the structure. Eurocode 3 Part 1-8 refers [17], for the characterization of the joint mechanical response to the component method based on some different researches and amongst them Jaspart [10]. Nassani and Chikho [18] presented a formula to calculate the column ultimate load to simulate the behaviour of steel columns in sway structures. The structural benefits of using semi-rigid joints are widely recognized and there is nowadays a general agreement to include the beam-column joint deformations in structural analysis. Various approaches are provided to include such an effect, for instance the finite element method $[19,20]$.The elastic stability of steel frames taking into account the effect of the joint flexibility and the elastic member instability are specific aspects to investigate.

Several authors [21-29] have presented models for determining the effective length factor of a beam-column with end restraints. Ermopoulos [21] presented a model for determining an equivalent buckling length of compression columns with semi rigid joints. Essa [22] proposed a design method for the evaluation of the effective length for columns in unbraced multistory frames. Raftoyiannis [23] presented the effects of the joint flexibility and elastic bracing system on the buckling load. Mageirou and Gantes [24], Gantes and Mageirou [25] proposed a model of an individual column representing a multistory frame where the member contributions converging at the bottom and top ends of the column are represented by equivalent springs. $\mathrm{Xu}$ and Liu [26] proposed a method for the stability analysis of semi braced steel frames with the effect of semi-rigid connections and the procedure of evaluating column effective length. $\mathrm{Xu}$ [27] presented a linear programming method to investigate stability strengths of unbraced steel frames subjected to variable loading, where the problem of determining the elastic buckling loads is expressed as a pair of maximization and minimization problems with stability constraints. A number of other alternative approximate effective length formulas are available in the literature; an overview is given in Hellesland [28] where it is shown how such formulas may be applied in system instability analysis of frames and comparisons with the exact effective length results have been carried out for 
isolated members. Cao et al. [29] presented a mechanical model of spring hinge ended column and design formulas to predicate the effective length factors were proposed.

\section{Significance of the research}

Chen et al. [30] proposed in an implicit form the stability functions derived from a slopedeflections approach. However, using the beam-column stiffness degradation approach and the stability functions, divergence occurs when the axial force of member is close to zero. A great deal of information on this subject have been presented by Chen et al.[30]. The proposed model however, is based on functions accounting for semi-rigid connections and predominant axial load, with an explicit formulation. Therefore, the formulation has the advantage of being explicit and simple to use, leading to very good results as is shown in the succeeding sections.

\section{Basic assumptions}

A previous study carried out by Shayan et al. [31] has shown that the effects of the residual stresses and initial imperfections on the buckling load are of the order of $2 \%$ and less than $1 \%$, respectively. Out-plane-effects were not considered as the study is only concerned with a two dimensional formulation of the problem. Furthermore, the axial load is applied through the centerline of the beam, and therefore no eccentricity is included in the analysis. GiraldoLondono et al. [32] investigated the post-buckling and large deflections of beam-columns with non-linear semi-rigid connections, taking into consideration shear and axial effects. The authors obtained good results for the study of large-deflection and post-buckling behaviour of Timoshenko beam-columns with non-linear bending connections. Stamatopoulos [33] modeled a plane frame with the supports consisting of non-linear rotational and translational springs, employing an energy approach. The author obtained limit values for the rotational stiffness for which the flexible supports affect the buckling response of the frame.

Gorgun [34] presented a computer-based analytical method for geometrically nonlinear frames with semi-rigid beam-to-column connections, employing modified stability functions to model the effect of axial force on the stiffness of members. The linear and nonlinear analyses were applied for two planar steel structures. However, the stability functions are not specifically given in the model adopted. Nguyen and Kim [35] presented a numerical procedure based on the beam-column method for nonlinear elastic dynamic analysis of three- 
dimensional semi-rigid steel frames. Geometric nonlinearity is considered through the use of stability functions and geometric stiffness matrix. An independent hardening model is adopted to capture the dynamic behavior of rotational. The authors used the SAP2000 software to verify the accuracy and efficiency of the proposed analysis through four numerical examples, but no validation against test results is presented.

MacRae et al. [36] have shown that in the elastic range, axial shortening may be safely ignored, and becomes more important once yielding in the members had occurred. As the current study is only concerned with investigating the elastic buckling, axial shortening is therefore ignored. Wongkaew and Chen [37] considered inelastic out of plane lateral torsional buckling in the advanced analysis for planar steel frame design. The authors showed that outof-plane buckling is likely to govern the strength of non-sway frames and may control the design of some sway frames. As such, it is important that out-of-plane buckling is considered in advanced analysis, post-linear. However, in this linear elastic study, and for simplicity, lateral torsional buckling has not been considered, as the frames analyzed are assumed to be adequately restrained against the development of lateral torsional buckling failure, as is commonly the case in civil engineering structures.

Hence, the following assumptions were made in the development of the mathematical formulation of the model: (i) members are initially straight, piecewise prismatic; (ii) plane cross section remains plane after deformation; (iii) local buckling and lateral torsional buckling are not considered (since the problem is two-dimensional one); (iv) the panel zone deformation of the joint is neglected; (v) the effect of residual stresses on the system response (especially critical load) is ignored.

\section{Mechanical model}

The mechanical model adopted (Ihaddoudène [16]) is based on the analogy of three springs. A beam element subjected to both a compression axial force $N$ and bending moments $M_{i}$ and $M_{j}$ with semi-rigid joints (Fig.1 and Fig.2) at each end, is considered.

\subsection{Equilibrium equations of an element}


4.1.1 Beam element under unit rotation $\theta_{i}=1$

Horizontal force equilibrium

$$
H_{i}=H_{j}=H
$$

Moment equilibrium at the distance $x$

$$
M(x)=N y+H x-M_{j}
$$

Moment equilibrium at end " $i$ "

$$
M_{i}=H l-M_{j}
$$

The equilibrium of this column in its buckled condition is described

$$
\begin{gathered}
E I y^{\prime \prime}=-N y-H x+M_{j} \\
y^{\prime \prime}+\alpha^{2} y=-\frac{H x}{E I}+\frac{M_{j}}{E I}
\end{gathered}
$$

where

$$
\alpha^{2}=\frac{N}{E I}
$$

The general solution of equation (5) is

$$
y(x)=A \sin \alpha x+B \cos \alpha x-\frac{H x}{\alpha^{2} E I}+\frac{M_{j}}{\alpha^{2} E I}
$$

where $A$ and $B$ are the constants of integration to be determined from the boundary conditions for $y(0)=0$ and $y(l)=0$

The deflection may then be rewritten as :

$$
y(x)=\frac{\sin \alpha x}{\alpha^{2} E I \sin \alpha l}\left[M_{j}(\cos \alpha l-1)+H l\right]-\frac{M_{j}}{\alpha^{2} E I} \cos \alpha x-\frac{H x}{\alpha^{2} E I}+\frac{M_{j}}{\alpha^{2} E I}
$$

and its first derivative is:

$$
y^{\prime}(x)=\frac{\cos \alpha x}{\alpha E I \sin \alpha l}\left[M_{j}(\cos \alpha l-1)+H l\right]+\frac{M_{j}}{\alpha E I} \sin \alpha x-\frac{H}{\alpha^{2} E I}
$$


The end reactions $H$ and $M_{j}$ are, hence, determined from the boundary conditions $y^{\prime}(0)$ and $y^{\prime}(l)$ which give the system of equations as:

$$
\left\{\begin{array}{l}
-\alpha M_{j}(1-\cos \alpha l)-H(\sin \alpha l-\alpha l)=k_{2} M_{j} \alpha^{2} E I \sin \alpha l \\
\alpha M_{j}\left(1-\cos \alpha l+k_{1} \alpha E I \sin \alpha l\right)+H\left(\alpha l \cos \alpha l-\sin \alpha l-k_{1} \alpha^{2} E I l \sin \alpha l\right)=-\alpha^{2} E I \sin \alpha l
\end{array}\right\}
$$

By setting

$$
\begin{aligned}
v=\alpha l & =l \sqrt{\frac{N}{E I}} \\
\text { and } \quad w & =\frac{E I}{l}
\end{aligned}
$$

where $E I$ and $l$ are respectively the flexural flexibility and the length of a beam element The system of equations (10) becomes:

$$
\left\{\begin{array}{l}
-\alpha M_{j}\left(1-\cos v+k_{2} v w \sin v\right)-H(\sin v-v)=0 \\
\alpha M_{j}\left(1-\cos v+k_{1} v w \sin v\right)+H\left(v \cos v-\sin v-k_{1} v^{2} w \sin v\right)=-\alpha^{2} E I \sin v
\end{array}\right\}
$$

The solution of this system of equations is given by:

$$
\begin{aligned}
& H=\frac{w}{l} \zeta_{1}(v) \\
& M_{j}=w \phi_{1}(v) \\
& M_{i}=w \phi_{2}(v)
\end{aligned}
$$

in which :

$$
\begin{aligned}
& \zeta_{1}(v)=\frac{v^{2}\left(1-\cos v+k_{2} v w \sin v\right)}{D} \\
& \phi_{1}(v)=\frac{v(v-\sin v)}{D} \\
& \phi_{2}(v)=\zeta_{1}(v)-\phi_{1}(v)
\end{aligned}
$$

Where

$$
D=(2-2 \cos v-v \sin v)+\xi\left(v, k_{1}, k_{2}\right)
$$

Table (1) below covers particular situations in terms of joint types at both ends. 


\subsubsection{Beam element under unit displacement $\Delta_{i}=1$}

A similar procedure is conducted for the beam element of the Fig.(2), the reaction $H$ and the moment equilibrium at the distance $x$ has the same expressions as given respectively by the Eq.(1) and Eq.(2); the expression of the moment $M_{i}$ is given as (Ihaddoudène and Jaspart [38]):

$$
M_{i}=N+H l-M_{j}
$$

The constants of integration to be determined for the Eq. (7) are obtained from the boundary conditions of $y(0)=0$ and $y(l)=1$

The deflection and its derivative may then be rewritten respectively as:

$$
\begin{aligned}
& y(x)=\frac{\sin \alpha x}{\alpha^{2} E I \sin \alpha l}\left[M_{j}(\cos \alpha l-1)+H l+\alpha^{2} E I\right]-\frac{M_{j}}{\alpha^{2} E I} \cos \alpha x-\frac{H x}{\alpha^{2} E I}+\frac{M_{j}}{\alpha^{2} E I} \\
& y^{\prime}(x)=\frac{\cos \alpha x}{\alpha E I \sin \alpha l}\left[M_{j}(\cos \alpha l-1)+H l+\alpha^{2} E I\right]+\frac{M_{j}}{\alpha E I} \sin \alpha x-\frac{H}{\alpha^{2} E I}
\end{aligned}
$$

The reactions $H$ and $M_{j}$ are determined from the boundary conditions of $y^{\prime}(0)$ and $y^{\prime}(l)$ for:

$$
\begin{aligned}
& y^{\prime}(0)=k_{2} M_{j} \\
& y^{\prime}(l)=k_{1} M_{i}=k_{1}\left(H l+N-M_{j}\right)
\end{aligned}
$$

The solution of the equation system formed gives the functions in the simplified form as follows:

$$
\begin{aligned}
& H=\frac{w}{l^{2}} \zeta_{2}(v) \\
& M_{j}=\frac{w}{l} \phi_{3}(v) \\
& M_{i}=\frac{w}{l} \phi_{4}(v)
\end{aligned}
$$

Tables (2), (3), and (4) give the expression of the coefficients used in Eq.(17) to Eq.(19) for different boundary conditions at both ends. 
It is worth noting that for the situation of clamped ends $\left(k_{1}=k_{2}=0\right)$, neglecting the deformation of the joints, the expressions are the same of those given in table (1). For pinned ends, $k_{1}=k_{2}=\infty, \zeta_{2}(v)=-v^{2}, \phi_{3}(v)=\phi_{4}(v)=0$.

\section{Stiffness matrix of an element}

In order to establish the modified stiffness matrix including both the effects of axial force and connection flexibility, one needs to consider different situations.

In the local reference system, the stiffness matrix which is represented by the nodal degrees of freedom $\left(\overline{V_{1}}, \overline{\theta_{1}}, \overline{V_{2}}, \overline{\theta_{2}}\right)$ of an element is given by:

$$
\overline{K_{e}}=\left[\begin{array}{llll}
k_{11} & k_{12} & k_{13} & k_{14} \\
k_{21} & k_{22} & k_{23} & k_{24} \\
k_{31} & k_{32} & k_{33} & k_{34} \\
k_{41} & k_{42} & k_{43} & k_{44}
\end{array}\right]
$$

The nodes of the beam which are represented by non deformable nodes at each ends $[13,15$, 16, 38] have different flexibilities $k_{1}$ and $k_{2}$ at both ends $i$ and $j$ respectively. In order to establish the different elements of the stiffness matrix $\overline{K_{e}}$ in local reference system, equilibrium equations and rotational deformations are considered for each element $k_{i j}$.

\subsection{Elements $k_{2 j}$}

The terms $k_{i j}$ of the stiffness matrix have been derived by establishing the equilibrium equations and rotational deformations of an element with semi rigid joints subjected to axial forces $N$ and moments $M_{i}, M_{j}$ at each of the ends " $i$ " and " $j "$.

From established equations (12), (13) and (14), the terms $k_{2 j}$ of the stiffness matrix may be derived by considering the equilibrium equations of an element such shown in Fig. (3).

$$
k_{21}=\frac{w}{l} \cdot \zeta_{1}(v)=\frac{w}{l} \cdot \frac{v^{2}\left(1-\cos v+k_{2} v w \sin v\right)}{D}
$$




$$
\begin{aligned}
& k_{22}=w \cdot \phi_{2}(v)=w \frac{v\left(\sin v-v \cos v+k_{2} v^{2} w \sin v\right)}{D} \\
& k_{23}=-k_{21} \\
& k_{24}=w \cdot \phi_{1}(v)=w \frac{v(v-\sin v)}{D}
\end{aligned}
$$

The same procedure is followed to derive all the terms of stiffness the matrix $\overline{K_{e}}$ of an element-which is given below:

$$
\left[\overline{K_{e}}\right]=E I\left[\begin{array}{cccc}
\frac{v^{3}(s+\Omega)}{D l^{3}} & -\frac{v^{2}\left(1-c+\eta_{2}\right)}{D l^{2}} & -\frac{v^{3}(s+\Omega)}{D l^{3}} & \frac{v^{2}\left(1-c+\eta_{1}\right)}{D l^{2}} \\
\frac{v\left(s-v c+v \eta_{2}\right)}{D l} & \frac{v^{2}\left(1-c+\eta_{2}\right)}{D l^{2}} & \frac{v(v-s)}{D l} \\
S Y M & \frac{v^{3}(s+\Omega)}{D l^{3}} & \frac{v^{2}\left(1-c+\eta_{1}\right)}{D l^{2}} \\
& & \frac{v\left(s-v c+v \eta_{1}\right)}{D l}
\end{array}\right]
$$

with:

$$
\begin{aligned}
& \Omega=\left(k_{1}+k_{2}\right) v w c-k_{1} k_{2}(v w)^{2} s \\
& \eta_{1}=k_{1} v w s \\
& \eta_{2}=k_{2} v w s
\end{aligned}
$$

"s" and "c" are sin and cos of an angle.

\subsection{Different boundary conditions at the ends of the element}

For some different boundary conditions, the particular elements $k_{2 j}$ above $(\mathrm{j}=1,2,3,4)$ are considered below:

5.2.1. Element $k_{2 j}$, when the joints are rigid with the presence of axial forces :

If the deformation of the joints is neglected then, $k_{1}=k_{2}=0$, the elements $k_{2 j}$ of the stiffness matrix are reduced to the well known expressions :

$$
\begin{aligned}
& k_{21}=H=\frac{E I}{l^{2}} \frac{v^{2}(1-c)}{(2-2 c-v s)} \\
& k_{22}=M_{i}=\frac{E I}{l} \frac{v(s-v c)}{(2-2 c-v s)}
\end{aligned}
$$




$$
\begin{aligned}
& k_{23}=-k_{21} \\
& k_{24}=M_{j}=\frac{E I}{l} \frac{v(v-s)}{(2-2 c-v s)}
\end{aligned}
$$

The stiffness matrix in the local reference system can be obtained as:

$$
\left[\overline{K_{e}}\right]=E I\left[\begin{array}{cccc}
\frac{v^{3} s}{l^{3}(2-2 c-v s)} & -\frac{v^{2}(1-c)}{l^{2}(2-2 c-v s)} & -\frac{v^{3} s}{l^{3}(2-2 c-v s)} & \frac{v^{2}(1-c)}{l^{2}(2-2 c-v s)} \\
\frac{v(s-v c)}{l(2-2 c-v s)} & -\frac{v^{2}(1-c)}{l^{2}(2-2 c-v s)} & \frac{v(v-s)}{l(2-2 c-v s)} \\
S Y M & & \frac{v^{3} s}{l^{3}(2-2 c-v s)} & -\frac{v^{2}(1-c)}{l^{2}(2-2 c-v s)} \\
& & \frac{v(s-v c)}{l(2-2 c-v s)}
\end{array}\right]
$$

5.2.2. Element $k_{2 j}$, when joints are semi rigid and no axial forces are present

In contrast, if the axial force is neglected and the deformation of the joint are considered with $k_{1}$ and $k_{2}$ at ends " $i "$ and " $j "$ respectively, the element $k_{2 j}$ of the modified stiffness matrix established [13]:

$$
\begin{aligned}
& k_{21}=-\frac{18 w\left(1+2 k_{2} w\right)}{l\left[4\left(1+3 k_{1} w\right)\left(1+3 k_{2} w\right)-1\right]} \\
& k_{22}=\frac{12 w\left(1+3 k_{2} w\right)}{4\left(1+3 k_{1} w\right)\left(1+3 k_{2} w\right)-1} \\
& k_{23}=-k_{21} \\
& k_{24}=\frac{6 w}{4\left(1+3 k_{1} w\right)\left(1+3 k_{2} w\right)-1}
\end{aligned}
$$

The stiffness matrix of an element may be obtained as follows:

$$
\left[\overline{K_{e}}\right]=\left[\begin{array}{cccc}
\frac{36 w\left[1+\left(k_{1}+k_{2}\right) w\right]}{D_{1} l^{2}} & -\frac{18 w\left(1+2 k_{2} w\right)}{D_{1} l} & -\frac{36 w\left[1+\left(k_{1}+k_{2}\right) w\right]}{D_{1} l^{2}} & -\frac{18 w\left(1+2 k_{1} w\right)}{D_{1} l} \\
\frac{12 w\left(1+3 k_{2} w\right)}{D_{1}} & \frac{18 w\left(1+2 k_{2} w\right)}{D_{1} l} & \frac{6 w}{D_{1}} \\
S Y M & & \frac{36 w\left[1+\left(k_{1}+k_{2}\right) w\right]}{D_{1} l^{2}} & \frac{18 w\left(1+2 k_{1} w\right)}{D_{1} l} \\
& & & \frac{12 w\left(1+3 k_{1} w\right)}{D_{1}}
\end{array}\right]
$$


Where, $D_{1}=4\left(1+3 k_{1} w\right)\left(1+3 k_{2} w\right)-1$

In order to establish the different elements of the stiffness matrix in $\overline{K_{e}}$ in local reference system, expressions have been derived by considering only the equilibrium equations and boundary conditions for each element $k_{i j}$ as presented in reference (Ihaddoudène et al. [15]). The expressions presented are more general and useful as they take all varieties of situations of the joints: considering or neglecting the semi-rigidity of joints and axial forces or combining them in any situation from stability functions established.

\section{Examples}

Some examples previously published $[24,25]$ are presented, for which the proposed approach is demonstrated and the results are compared and validated.

In this section, the critical buckling load is determined for different sway and non-sway frames (Ihaddoudène[16], Ihaddoudène and Jaspart [38]).

The following three examples discussed are taken from the reference [24, 25] where the characteristics of the structural elements are given below:

For the beam $\left\{\begin{array}{l}E I=48573 k N . m^{2} \\ E A=896490 k N\end{array}\right\}$ and for the column $\left\{\begin{array}{l}E I=90699 k N . m^{2} \\ E A=1272600 k N\end{array}\right\}$

and the flexibility $k_{1}=1 / 150 \mathrm{rad} / \mathrm{kN} . \mathrm{m}$

\subsection{Non-sway frame}

The steel frames shown in figure (4) are analyzed and compared with different results given in the references $[24,25]$. The analysis of the results is given in the tables (5) and (6) below.

The buckling load obtained by the present study, for both cases, is the same as the one obtained by the cited references. It is reached when the stiffness matrix is singular (i-e. determinant is zero). 
Despite the different boundary conditions for the beam in case (a) and case (b) in Figure (4), the results reported in Table (5) and Table (6) are quite similar. In fact, the semi-rigid joint acting at the upper extremity of the column possesses a very low stiffness in comparison to the one of the beam and should be classified as "pinned" according Eurocode 3 part 1-8 [17]. This explains why the boundary conditions at the right extremity of the beam are not influencing significantly the critical cases for case (a) and case (b).

\subsection{Multistory sway frame}

The multistory frame of figure (5) is analyzed using the proposed formulation compared to those given by the reference [24]. Table (7) below gives the buckling load values obtained for different methods.

The table above (7) summarizes the value of the critical load obtained by different methods. The proposed method gives the value of $P_{c r}=21.94 k N$, identical to those given by the finite element method (22.02428 $k N)$ and by the authors $(21.9399 k N)$ and is in very good agreement with not only finite element results but Eurocode 3 results as well [17]. This was not the case for "EC3 as cited in the reference [24]". This results from the fact that this EC3 evaluation is based on the assumption of rigid beam-to-column joints. An improvement of this procedure aiming at accounting for the presence of sem-rigid joints is expressed in [40].

\subsection{Sway and non-sway frame}

The two situations of sway and non sway frames shown in figures (6a) and (6b) are considered, respectively. Tables (8) and (9) give the value of the critical load obtained for these two cases using the different considered methods.

For the sway frame, the critical load obtained by the proposed method is very close to that given by Mageirou and Gantes [24] and is respectively equal to $P_{c r}=14.7 \mathrm{kN}$ and $P_{c r}=14.77 \mathrm{kN}$ and is in a good agreement with that obtained with the method clause 5.2.1(4)B of EC3 [17].

The results as reported in the reference (Gantes and Mageirou [25]) ( See Tables 7 and 8 ) calculated with Eurocode 3 [17] for sway and non-sway frames are very different from those obtained by the authors with EC3 clause 5.2.1(4)B [17]. 
The results obtained using this analytical formulation are clearly consistent with those obtained by the above references, the finite element method and the application of EC3 clause 5.2.1(4)B for both sway and non sway frames. The formulation provides a simple solution for each of the design situations that refer to the concept of elastic critical resistance.

\section{Conclusions}

A simple effective mechanical model for determining the elastic buckling load for both sway and non-sway multistory plane steel frames with semi-rigid connections was proposed and a corresponding stiffness matrix presented.

The novelty of the model consisted in the development of comprehensive approach taking into account, simultaneously, the effects of the joint rigidity and the elastic buckling load, and this for both sway and non-sway frames. Only one element is sufficient over the length of the element to model stability. Numerical results are obtained for frames with various characteristics and support conditions when three illustrative examples from the literature are presented and discussed.

Illustrative published examples of frames are presented and examined, and comparison between the results gives a good correlation, suggesting that the proposed model is adequate and may be a useful tool in the analysis of steel frames with semi-rigid joints. Additionally, the results obtained using the proposed method agrees well with those obtained by other approaches, however the present method is much simpler to use and apply for a wide range of conditions. It is shown that joint flexibility is a very important parameter that needs to be incorporated into the instability analysis of frames with semi-rigid joints.

In previous work carried by other researchers, e.g. [24], concerning the application of EC3, is that it ignores the effect of the rigidity of the joints in the evaluation of the critical load, which explains the difference in the results. Furthermore, as the reference structures are almost a mechanism because of the rather low joint stiffness, the determination of the critical load is very sensitive to the rigidity of the joint. Nevertheless, the current approach gives very good results, making it a comprehensive, effective and reliable technique to use for two dimensional steel frames with semi-rigid joints, with or without sway, with the problem of 
instability taken into consideration. Thus, $\mathrm{P}-\delta$ effects can easily be taken into account using the current model.

\section{References}

[1] Chisala ML. "Modelling $M-\phi$ curves for standard beam-to-column connections". Engineering Structures, 1999; 21: 1066-1075. DOI: 10.1016/S0141-0296(98)00033-9.

[2] Sang-Sup L, Tae Sup M. "Moment-rotation model of semi rigid connections with angles". Engineering Structures, 2002; 24: 227-237. DOI:10.1016/S0141- 0296(01)00066-9.

[3] Shi Y, Shi G, Wang Y. "Experimental and theoretical analysis of the moment-rotation behaviour of stiffened extended end-plate connections". Journal of Constructional Steel Research, 2007; 63: 1279-1293. DOI: 10.1016/j.jcsr.2006.11.008.

[4] Pirmoz A, Seyed Khorei A, Mohammadrezapour E, Daryan AS. "Moment-rotation behavior of bolted top-seat angle connections". Journal of Constructional Steel Research, 2009; 65: 973-984. DOI: 10.1016/j.jcsr.2008.08.011.

[5] Cabrero JM, Bayo E. "Development of practical design methods for steel structures with semi-rigid connections”. Engineering Structures, 2005; 27: 1125-1137.

[6] Pucinotti R. "Top-and-seat and web angle connections: prediction via mechanical model”. Journal of Constructional Steel Research, 2001; 57: 661-694. DOI: 10.1016/S0143974X(01)00007-4.

[7] Simoes da Silva L, Girao Coelho AM. "An analytical evaluation of the response of steel joints under bending and axial force". Computers \& Structures, 2001; 79: 873-881.

[8] Lui EM, Chen WF. "Behavior of braced and unbraced semi-rigid frames". International Journal of Solids and Structures, 1988; 24: 893-913. 
[9] Diaz C, Marti P, Victoria M, Querin OM. "Review on the modelling of joint behaviour in steel frames". Journal of Constructional Steel Research, 2011; 67:741-758. DOI: 10.1016/j.jcsr.2010.12.014

[10] Jaspart JP.”Design of structural joints in building frames”. Progress in Structural Engineering and Materials, 2002; 4 (1):18-34. DOI: 10.1002/pse.105.

[11] Lui EM, Chen, WF. "Effects of joint flexibility on the behavior of steel frames". Computers Structures, 1987; 26(5): 719-723. DOI:10.1016/0045-7949(87)90021-6.

[12] Simoes da Silva, L. "Towards a consistent design approach for steel joints under generalized loading”. Journal of Constructional Steel Research, 2008; 68: 1059-1075.

[13] Ihaddoudène ANT, Saidani M, Chemrouk M. "Modelling of steel frames with semi rigid joints". International Journal of Applied Engineering Research, 2008, 3(7): 955-967. DOI, 10.1016/j.jcsr.2008.08.010

[14] Del Savio AA, Nethercot DA, Vellasco PCGS, Andrade SAL, Martha LF. "Generalised component-based model for beam-to-column connections including axial versus moment interaction”. Journal of Constructional Steel Research, 2009; 65: 1876-1895.

[15] Ihaddoudène ANT, Saidani M, Chemrouk M. "Mechanical model for the analysis of steel frames with semi rigid joints". Journal of Constructional Steel Research, 2009; 65: 631640.

[16] Ihaddoudène ANT. "Analyse de la stabilité des structures à assemblages semi-rigides", Ph.D Thesis, Faculty of Civil Engineering, University of Sciences and Technology, U.S.T.H.B, Algeria, 2008.

[17] Eurocode 3: Design of Steel Structures - Part 1-8: Design of joints, Brussels, CEN, 2005. 
[18] Nassani DE, Chikho AH. "A simple formula for estimating the column; ultimate load with effect of semi-rigid connections". International Journal of Steel Structures, 2015; 15(1):31-38.

[19] Thai H, Kim S. "Second-order distributed plasticity analysis of steel frames with semirigid connections". Thin-Walled Structures, 2015; Issue 4, No.11:120-128.

[20] Kaushik K, Sharma AK, Kumar R. "Modelling and FE analysis of column to beam end plate bolted connection ”. Engineering Solid Mechanics Journal, 2014; 2(1): 51-66.

[21] Ermopoulos J. "Buckling length of framed compression members with semi rigid connections ”. Journal of Constructional Steel Research, 1991;18(2):139-54.

[22] Essa HS: "Stability of columns in unbraced frames". Journal of Structural Engineering, 1997;123(7): 952-957.

[23] Raftoyiannis IG “ The effect of semi-rigid joints and an elastic bracing system on the buckling load of simple rectangular steel frames". Journal of Constructional Steel Research, 2005; 61: 1205- 1225. DOI: 10.1016/j.jcsr.2005.01.005.

[24] Mageirou GE, Gantes CJ. "Buckling strength of multi-story sway, non-sway and partially-sway frames with semi-rigid connections". Journal of Constructional Steel Research, 2006; 62: 893-905. DOI: 10.1016/j.jcsr.2005.11.019.

[25] Gantes CJ, Mageirou GE. "Improved stiffness distribution factors for evaluation of effective buckling lengths in multi-story sway frames". Engineering Structures, 2005; 27:1113-1124.

[26] Xu L, Liu Y. "Story stability of semi-braced steel frames". Journal of Constructional Steel Research, 2002; 58(4): 467-491.

[27] Xu L. "The buckling loads of unbraced PR frames under non-proportional loading". Journal of Constructional Steel Research, 2002; 58(4): 443-465. 
[28] Hellesland J. "Evaluation of effective length formulas and applications in system instability analysis". Engineering Structures, 2012; 45: 405-420.

[29] Cao K., Guo YJ, Xu J. "Buckling analysis of columns ended by rotation-stiffness spring hinges". International Journal of Steel Structures, 2016; 16(1): 1-9.

[30] Chen W.F., Kishi N., Komuro M. "Semi-rigid connections handbook". J. Ross Publishing, Civil and Environmental Engineering Series. 2011.

[31] Shayan S, Rasmussen K Jr, Zhang H. "On the modeling of initial geometric imperfections and residual stress of steel frames”. Research Report R935, September 2012. The University of Sydney.

[32] Giraldo-Londono O, Aristizabal-Ochoa JD, Giraldo JSM. "Large-deflection and postbuckling of beam-columns with non-linear semi-rigid connections including shear and axial effects". International Journal of Non-linear Mechancics, 2015; 77:85-95.

[33] Stamatopoulos GN. "Influence of the flexible supports on the buckling loads of steel frames". International Journal of Steel Structures, 2015; 15:661-670.

[34] Gorgun H. "Geometrically nonlinear analysis of plane frames composed of flexibly connected members". Structural Engineering and Mechanics, 2013; 45: 273-305.

[35] Nguyen PC, Kim SE. "Nonlinear elastic dynamic analysis of space steel frames with semi-rigid connections". Journal of Constructional Steel Research, 2013; 84: 72-81.

[36] MacRae GA, Urmson CR, Walpole WR, Moss P, Hyde K, Clifton C. "Axial shortening of

steel columns in buildings subjected to earthquakes". Bulletin of the New Zealand Society for Earthquake Engineering, December 2009; 42(4): 275-287.

[37] Wongkaew K, Chen WF. "Consideration of out-of-plane buckling in advanced analysis for planar steel frame design”. Journal of Constructional Steel Research, 2002; 58: 943-965. 
[38] Ihaddoudène ANT, Jaspart JP. "Stability of non sway steel frames with semi rigid connections ", Proceedings of the 14th International Conference on Civil, Structural and Environmental Engineering \& Computing, September 3-6, 2013. Cagliari, Italy

[39] WinOssa2D, ver.3.31: Elastic design of plane frames. University of Liège, Belgium.

[40] Maquoi R, Chabrolin B. "Frame design including joint behavior". Final report of ECCS Contract No 7210-SA/212/320, European Communities, Brussels, 1998. 
Table (1): Different types of joints at element extremities

\begin{tabular}{|c|c|c|c|}
\hline Element & 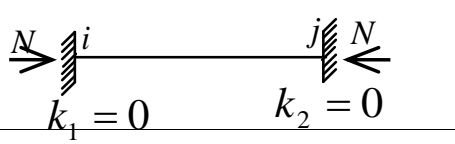 & 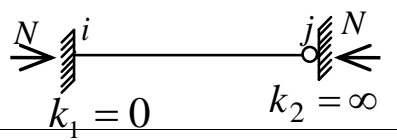 & $\underset{k_{2}}{j=\infty} \stackrel{j=\infty}{=}$ \\
\hline$\zeta_{1}(v)$ & $\frac{v^{2} \sin v}{2 \sin v-\cos v-v}$ & $\frac{v^{2} \sin v}{\sin v-v \cos v}$ & $\frac{v^{2} \sin v}{\sin v-v \cos v+k_{1} v^{2} w \sin v}$ \\
\hline$\phi_{1}(v)$ & $\frac{v \sin v(v-\sin v)}{(1-\cos v)(2 \sin v-\cos v-v)}$ & 0 & 0 \\
\hline$\phi_{2}(v)$ & $\frac{v \sin v(\sin v-v \cos v)}{(1-\cos v)(2 \sin v-\cos v-v)}$ & $\frac{v^{2} \sin v}{\sin v-v \cos v}$ & $\frac{v^{2} \sin v}{\sin v-v \cos v+k_{1} v^{2} w \sin v}$ \\
\hline
\end{tabular}


Table (2): Expressions of $\zeta_{2}(v), \phi_{3}(v)$ and $\phi_{4}(v)$ for different element boundary conditions

\begin{tabular}{|c|c|c|c|}
\hline Element & 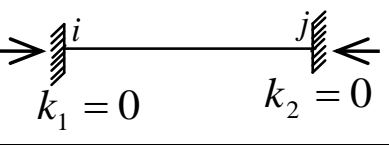 & $\begin{array}{c}\rightarrow g^{i} \\
k_{1}=0\end{array}$ & $\rightarrow$ 息 $_{k_{1}}^{i}$ \\
\hline$\zeta_{2}(v)$ & $\frac{v^{3}(1+\cos v)}{2 \sin v-v \cos v-v}$ & $\frac{v^{3} \cos v}{(\sin v-v \cos v)}$ & $\frac{v^{3}\left(\cos v-k_{1} v \omega \sin v\right)}{\left(\sin v-v \cos v+k_{1} v^{2} \omega \sin v\right)}$ \\
\hline$\phi_{3}(v)$ & $\frac{v^{2} \sin v}{2 \sin v-v \cos v-v}$ & 0 & 0 \\
\hline$\phi_{4}(v)$ & $\frac{v^{2} \sin v}{2 \sin v-v \cos v-v}$ & $\frac{v^{2} \sin v}{(\sin v-v \cos v)}$ & $\frac{v^{2} \sin v}{\left.\sin v-v \cos v+k_{1} v^{2} \omega \sin v\right)}$ \\
\hline
\end{tabular}


Table (3): Particular case of semi-rigid and fully rigid ends

\begin{tabular}{|c|c|}
\hline Element & 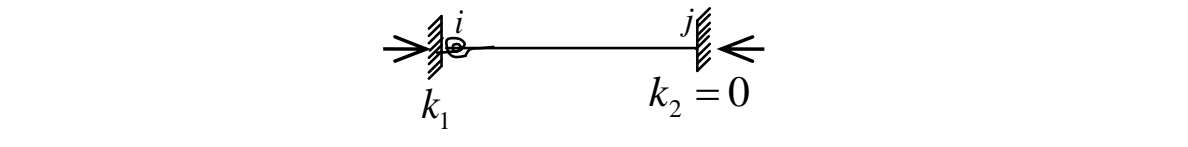 \\
\hline \multirow{2}{*}{$\zeta_{1}(v)$} & $v^{2} \sin v(1-\cos v)$ \\
\hline & $(1-\cos v)\left(\sin v-v \cos v+k_{1} v^{2} w \sin v\right)+(\sin v-v)\left(1-\cos v+k_{1} v w \sin v\right)$ \\
\hline \multirow{2}{*}{$\phi_{1}(v)$} & $v \sin v(v-\sin v)$ \\
\hline & $\overline{(1-\cos v)\left(\sin v-v \cos v+k_{1} v^{2} w \sin v\right)+(\sin v-v)\left(1-\cos v+k_{1} v w \sin v\right)}$ \\
\hline \multirow{2}{*}{$\phi_{2}(v)$} & $v \sin v(\sin v-v \cos v)$ \\
\hline & $\overline{(1-\cos v)\left(\sin v-v \cos v+k_{1} v^{2} w \sin v\right)+(\sin v-v)\left(1-\cos v+k_{1} v w \sin v\right)}$ \\
\hline \multirow{2}{*}{$\zeta_{2}(v)$} & $v^{3} \sin v\left(\sin v+k_{1} v \omega \cos v\right)$ \\
\hline & $(\sin v-v)(1-\cos v)+(\sin v-v \cos v)\left(1-\cos v+k_{1} v \omega \sin v\right)$ \\
\hline \multirow{2}{*}{$\phi_{3}(v)$} & $v^{2} \sin v\left(1-\cos v+k_{1} v \omega \sin v\right)$ \\
\hline & $(\sin v-v)(1-\cos v)+(\sin v-v \cos v)\left(1-\cos v+k_{1} v \omega \sin v\right)$ \\
\hline \multirow{2}{*}{$\phi_{4}(v)$} & $v^{2} \sin v(1-\cos v)$ \\
\hline & $(\sin v-v)(1-\cos v)+(\sin v-v \cos v)\left(1-\cos v+k_{1} v \omega \sin v\right)$ \\
\hline
\end{tabular}


Table (4): Particular case of fully rigid and semi-rigid ends

\begin{tabular}{|c|c|}
\hline Element & \multicolumn{1}{c}{$\rightarrow \hat{z}_{1}$} \\
\hline$\zeta_{1}(v)$ & $\frac{v^{2} \sin v\left(1-\cos v+k_{2} v \omega \sin v\right)}{\left(1-\cos v+k_{2} v \omega \sin v\right)(\sin v-v \cos v)+(\sin v-v)(1-\cos v)}$ \\
\hline$\phi_{1}(v)$ & $\frac{v \sin v(v-\sin v)}{\left(1-\cos v+k_{2} v \omega \sin v\right)(\sin v-v \cos v)+(\sin v-v)(1-\cos v)}$ \\
\hline$\phi_{2}(v)$ & $\frac{v \sin v\left(\sin v-v \cos v+k_{2} v^{2} \omega \sin v\right)}{\left(1-\cos v+k_{2} v \omega \sin v\right)(\sin v-v \cos v)+(\sin v-v)(1-\cos v)}$ \\
\hline$\zeta_{2}(v)$ & $\frac{v^{3}\left[(1-\cos v)+\cos v\left(1-\cos v+k_{2} v \omega \sin v\right)\right]}{\left(1-\cos v+k_{2} v \omega \sin v\right)(\sin v-v \cos v)+(\sin v-v)(1-\cos v)}$ \\
\hline$\phi_{3}(v)$ & $\frac{v^{2} \sin v(1-\cos v)}{\left(1-\cos v+k_{2} v \omega \sin v\right)(\sin v-v \cos v)+(\sin v-v)(1-\cos v)}$ \\
\hline$\phi_{4}(v)$ & $\frac{\zeta_{2}(v)-\phi_{3}(v)+v^{3}}{2}$ \\
\hline
\end{tabular}


Table (5): Comparison of the critical load values for the case (a)

\begin{tabular}{|c|c|c|}
\hline Methods used & $P_{c r}(k N)$ & $\frac{P_{c r}-P_{c r}, M E F}{P_{c r}, M E F}(\%)$ \\
\hline F.E.M- MSC-NASTRAN [24] & 8981.58 & 0 \\
\hline Reference [24] & 8981.16 & -0.005 \\
\hline Present proposed study & 8982 & 0.0046 \\
\hline
\end{tabular}


Table (6): Comparison of the critical load values for the case (b)

\begin{tabular}{|c|c|c|}
\hline Methods used & $P_{c r}(k N)$ & $\frac{P_{c r}-P_{c r}, M E F}{P_{c r}, M E F}(\%)$ \\
\hline F.E.M- MSC-NASTRAN [24] & 8979.83 & 0 \\
\hline Reference [24] & 8979.86 & 0.001 \\
\hline Present proposed study & 8980 & 0.0019 \\
\hline
\end{tabular}


Table (7): Critical load values obtained with different methods [24] and the present study.

\begin{tabular}{|c|c|c|}
\hline Methods used & $P_{c r}(k N)$ & $\frac{P_{c r}-P_{c r}, M E F}{P_{c r}, M E F}(\%)$ \\
\hline F.E.M- MSC-NASTRAN [24] & 22.02428 & 0 \\
\hline F.E.M - OSSA2D [39] & 21.98 & -0.2 \\
\hline EC3 [24] & 560.6 & 2445.37 \\
\hline EC3 clause 5.2.1 (4)B [17] & 21.74 & -0.0227 \\
\hline Reference [24] & 21.9399 & -0.38 \\
\hline Present proposed study & 21.94 & -0.382 \\
\hline
\end{tabular}


Table (8): Comparison of the critical load values for sway frame

\begin{tabular}{|c|c|c|}
\hline Methods used & $P_{c r}(k N)$ & $\frac{P_{c r}-P_{c r}, M E F}{P_{c r}, M E F}(\%)$ \\
\hline F.E.M - OSSA2D [39] & 14.76 & 0 \\
\hline EC3 [24] & 898.78 & 5983.56 \\
\hline EC3 clause 5.2.1 (4)B [17] & 14.76 & 0 \\
\hline Reference [24] & 14.77 & 0 \\
\hline Present proposed study & 14.7 & -0.406 \\
\hline
\end{tabular}


Table (9): Comparison of the critical load values for non sway frame

\begin{tabular}{|c|c|c|}
\hline Methods used & $P_{c r}(k N)$ & $\frac{P_{c r}-P_{c r}, M E F}{P_{c r}, M E F}(\%)$ \\
\hline F.E.M- MSC-NASTRAN [24] & 8980.67 & 0 \\
\hline F.E.M - OSSA2D [39] & 8739.5 & -2.7 \\
\hline EC3 [24] & 9980.74 & 11.14 \\
\hline EC3 Clause 5.2.1 (4)B [17] & 8987.5 & 0 \\
\hline Reference [24] & 8980.67 & -0.0008 \\
\hline Present proposed study & 8980.6 & 0 \\
\hline
\end{tabular}




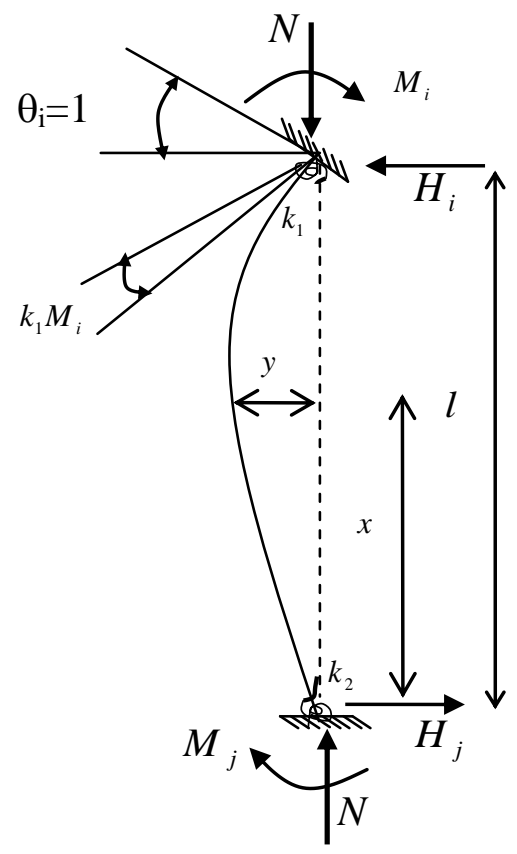

Figure (1): Beam element subjected to a unit rotation $\theta_{i}=1$ 


\section{igure 2}

Click here to download Figure: Figure 2.pdf

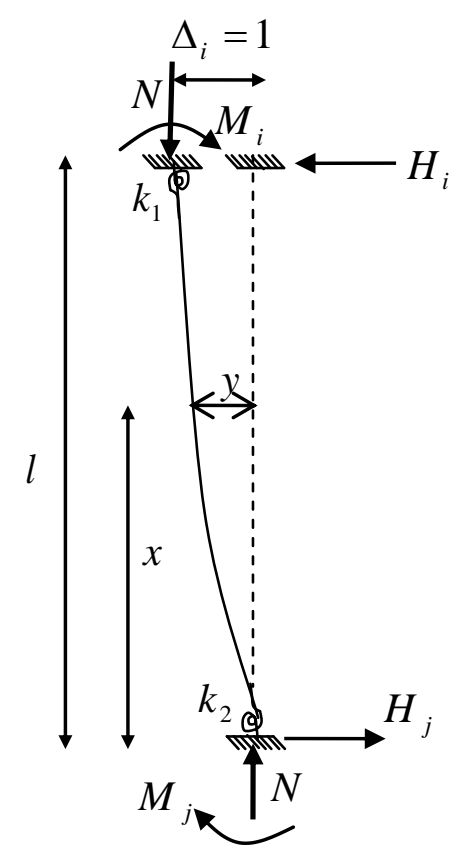

Figure (2): Beam element under unit displacement $\Delta_{\mathrm{i}}=1$ 
Figure 3

Click here to download Figure: Figure 3.pdf

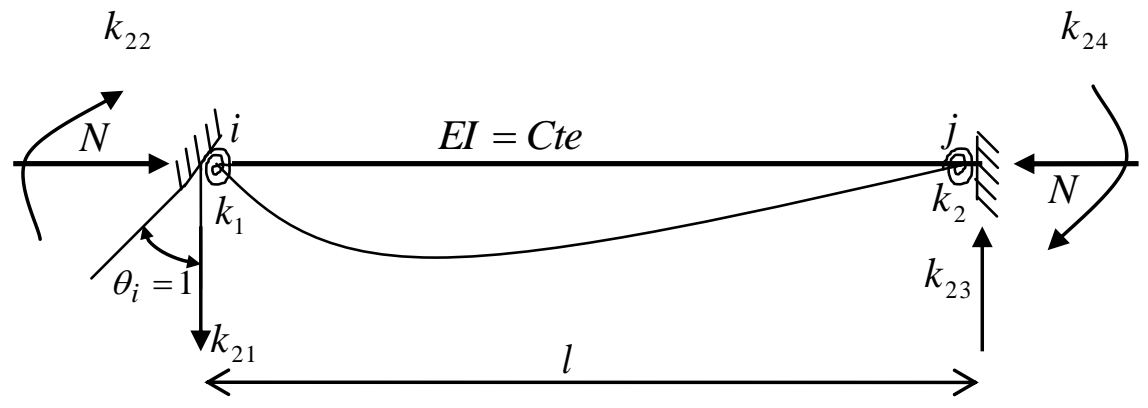

Figure (3): Element $k_{2 j}$ 


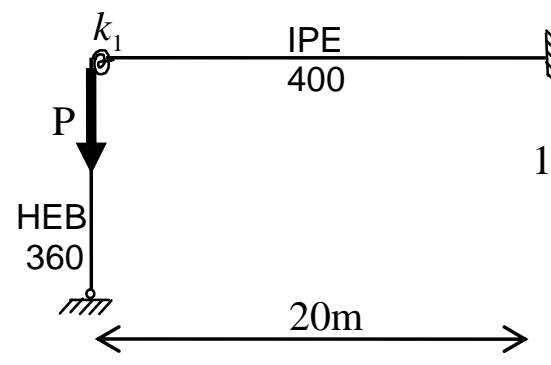

Case (a)

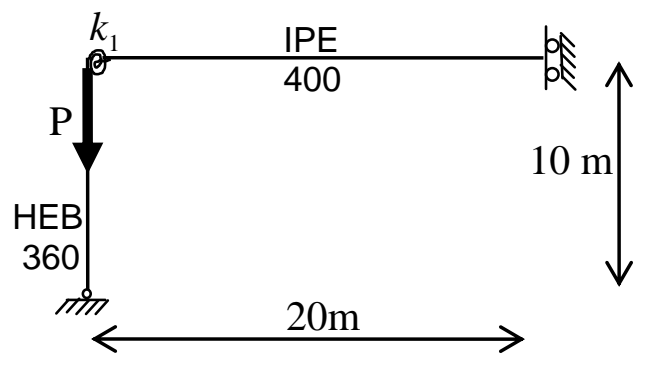

Case (b)

Figure (4): Studied systems [24] 


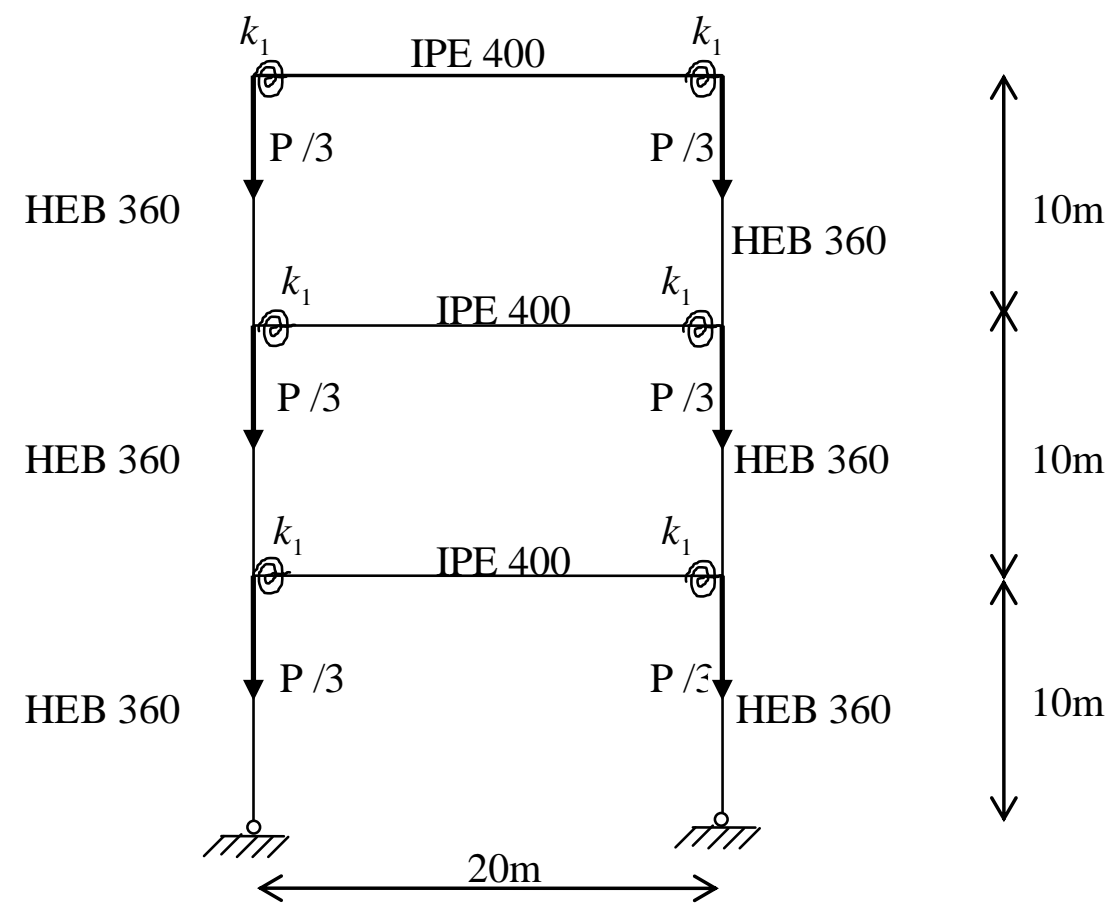

Figure (5): Multistory frame [24] 
Figure 6

Click here to download Figure: Figure 6.pdf

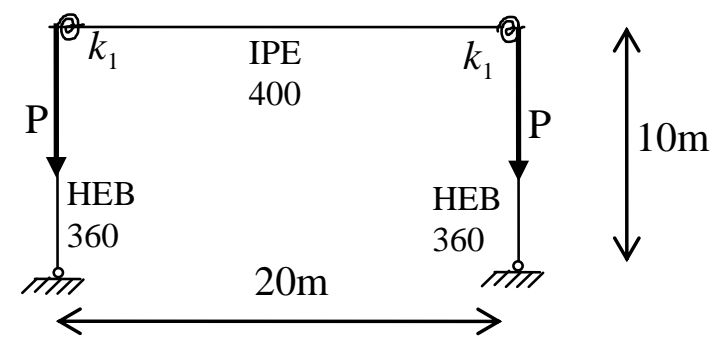

(a) : Sway frame

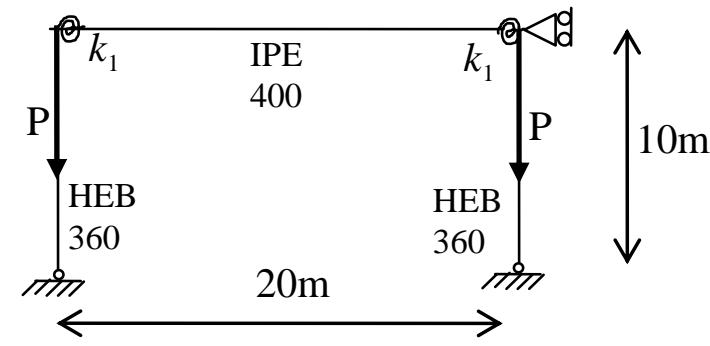

(b) : Non Sway frame

Figure (6): One story frame [24] 